\title{
Does too much liquidity generate instability?
}

\author{
Giorgio Calcagnini $^{1}$ - Laura Gardini ${ }^{1}$ - Germana Giombini ${ }^{1}$ (D) \\ Edgar S. Carrera ${ }^{1}$
}

Received: 5 March 2020 / Accepted: 8 August 2020 / Published online: 28 August 2020

(c) The Author(s) 2020

\begin{abstract}
Corporate demand for cash is related to a number of firm-specific characteristics, like the presence of transaction costs, information asymmetry in credit markets, uncertainty and risk aversion. The purpose of this paper is to build a dynamic model that describes the potential chaotic effects of the accumulation of cash by firms over a prolonged period of time. By exploring the theoretical connections between firm financial policies and investment decisions, we show that too much liquidity might generate economic instability. When firm increases the share of cash devoted to risky investment, and reduces the share of cash distributed to shareholders as dividends, the fixed point of the system changes from being stable to being unstable. Moreover, the impact of such a policy on the stability of the system is larger the greater the investment risk. The chaotic behavior is mainly observable in the dynamics of cash, which in turn may affect all investment decisions.
\end{abstract}

Keywords Corporate finance $\cdot$ Firm liquidity $\cdot$ Volatility $\cdot$ Instability $\cdot$ Chaos

\begin{abstract}
This paper benefited from comments and suggestions from participants at the: seminar held at the New College of Humanities, London, June 25 2019; '11-th NED Conference' held at the Kiev School of Economics on 4-6 September, 2019; and at the International Workshop "New Developments in Economic Dynamics" organized by DESP held in Urbino, November 5, 2019. Financial support from the research project on "Models of behavioral economics for sustainable development" financed by DESP-University of Urbino is gratefully acknowledged. The usual disclaimer applies.
\end{abstract}

$凶$ Germana Giombini germana.giombini@uniurb.it

Giorgio Calcagnini

giorgio.calcagnini@uniurb.it

Laura Gardini

laura.gardini@uniurb.it

Edgar S. Carrera

edgar.sanchezcarrera@uniurb.it

1 University of Urbino Carlo Bo, Urbino, Italy 


\section{Introduction}

The purpose of this paper is to build a dynamic model that describes the potential chaotic effects of the accumulation of cash by firms over a prolonged period of time. While firms loaded with relatively more liquid assets may attract, from time to time, more investors' and lenders' attention than firms with low levels of cash, the formerby holding cash-may miss investment opportunities and-prospectively-be less profitable than the latter. Indeed, investors may take the excessive amount of cash as a sign that opportunities for significant growth no longer exist or that, in an imperfect information environment, agency problems do exist, and the stock price may be poised to decline (Gilchrist and Himmelberg 1995; Gilchrist et al. 2009, 2013, Adler et al. 2019).

Therefore, traditional analyses of firms' yearly balance sheet are only partially informative of their ability to generate wealth/income for their shareholders, while a dynamic model provides a better setup to study the complex structure of relationships and equilibria that characterize firms over time.

Companies' holdings of liquid assets, mostly in the form of cash, have become a very timely issue. Both European and U.S. companies have accumulated substantial cash reserves on their balance sheets. Corporate cash holdings corrected for inflation increased almost six times from 1980 to 2017, from 140 to 811 bn dollars (see Adao and Silva 2019). ${ }^{1}$ Most recent data show that, for the main European countries (i.e., France, Germany, Italy and Spain) between 2007 and 2018, the aggregate nominal GDP and the stock of deposits held by non-financial firms increased by $16 \%$ and $90 \%$, respectively. ${ }^{2}$ Further, during the same period, U.S. non-financial companies increased their cash stockpiles from U.S.\$ 0.72 tn in 2007 to \$ $1.69 \mathrm{tn}$ in 2018, that is more than $230 \%$, while nominal GDP increased by $142 \% .^{3}$

Several explanations have been put forward to explain the accumulation of firm liquidity. Indeed, excessive cash is often just as bad as holding excessive debt. Money sitting unused creates opportunity costs, so boards typically want to use it to clear high interest debt, buy back shares, make acquisitions, or to increase dividends (Blanchard et al. 1994). At times of low interest rates, such as the one we are now experiencing, finance departments try hard to find short-term investments to park their excess cash and stock markets. The latter, because of their high volatility, are not always the best investment option and, as long as this volatility is driven by general and business uncertainty, they become riskier (Picard 2011). ${ }^{4}$ Therefore, high levels of available liquidity require renewed investment decisions and balance-sheet optimization strate-

\footnotetext{
${ }^{1}$ For instance, in aggregate terms, by the end of 2013, European non-financial firms held nearly $€ 500 \mathrm{bn}$., while the same for U.S.non-financial companies amounted to approximately $\$ 1.4$ tn (Gatti and Chiarella 2014; Sanchez and Yurdagul 2013).

2 Our calculations on data from the E.U. https://data.europa.eu/euodp/it/data.

${ }^{3}$ Our calculations on data from The Wall Street Journal https://www.wsj.com/articles/u-s-corporate-cashpiles-drop-to-three-year-low- 11560164400 and the World Bank https://data.worldbank.org/indicator/NY. GDP.MKTP.CD?locations=US.

${ }^{4}$ Most recent data show that global uncertainty has peaked, even in comparison with the years of the financial crisis (Ahir et al. 2018; Backer et al. 2019). Therefore, investing cash in M\&As or in the acquisition of new equipments is particularly risky.
} 
gies. Otherwise, firms will lose the benefits and opportunities, and take on excessive risks, that having too much cash poses (Gatti and Chiarella 2014).

From a theoretical point of view, the demand for money by firms has been brought to our attention by the work of Miller and Orr (1966, 1968), following the pioneering work of Baumol (1952) and Tobin (1956). While Miller and Orr recognized the similarity of the determinants of the demand for money of households and firms, they also noted that the typical pattern of firm cash management shows higher volatility than that of households. Indeed, firm managers decide to invest firms' cash balance (for instance, into temporary projects or to loan retirement) only beyond particular thresholds, which are typically larger than households'. As long as cash is somewhat related to sales, uncertainty about future economic prospects gives rise to a precautionary motive for firms for holding cash beyond the transactions demand for money (Frenkel and Jovanovic 1980). The former, stimulated by the recent financial crisis, may indeed be one of the main reasons behind the observed increase in firm holdings of liquid assets, which are thought to provide financial resilience and flexibility. Finally, the rise of a precautionary demand for money may also be related to the presence of market imperfections and financial constraints: firms have excessive holdings of cash to avoid the cost associated with the external-fundraising or the liquidation of existing assets to finance their growth opportunities (Almeida et al. 2004; Acharya et al. 2007; Campello et al. 2011).

As for the speculative motive, in modern corporations (especially among those of bigger size) the piling up of cash and its use is correlated to the presence of agency problems between owners and managers (or between controlling shareholders and outside investors). Indeed, equity holders would prefer that cash above the optimal buffer level of reserves be paid out, while managers may value the freedom from monitoring by external investors that this excessive cash provides them. A primary use of cash, which is preferred by managers, is acquisitions and other investments that may not be value increasing for the shareholders (Jensen and Meckling 1976; Jensen 1986; Harford 1999). Further, as already noted above, the quest for riskier investments is exacerbated during times of low yields from safe assets, such as Treasury bonds, which traditionally have been used to park excessive firm liquidity.

From an empirical point of view, the different determinants of firm cash holdings are analyzed by Kim et al. (1998), Opler et al. (1999), Ozkan and Ozkan (2004) and Dottori and Micucci (2018), among others. Corporate demand for cash is related to a number of firm-specific characteristics, like the presence of transaction costs, information asymmetry in credit markets, uncertainty and risk aversion (Bates et al. 2009; Calcagnini et al. 2009; Bover and Watson 2005). In the case of the U.S. economy, many commentators have argued that companies have been hoarding cash while postponing investment projects because of a poor regulatory climate and excessive uncertainty. Another frequently mentioned explanation for the high cash holdings of U.S. firms is that repatriation of cash held abroad by multinational corporations has adverse tax consequences, and, therefore, it is advantageous for them to keep their profits abroad in the form of cash (Pinkowitz et al. 2015). In this vein, Faulkender et al. (2019) show that cash holdings is not uniform across firms but is concentrated in the foreign subsidiaries of multinational firms. As foreign tax rates fell below U.S. rates, there has been an incentive not only to delay the repatriation of foreign income, but also to shift 
income into lower tax jurisdictions. Hence, the authors conclude that firms' domestic cash is mainly explained by precautionary savings variables, while taxes scheme explain firms' foreign cash growing, especially for firms with intellectual property. Across countries, firm cash holdings differ depending on firm characteristics, among which R\&D outlays (measured against sales) play an important role (Opler et al. 1999). Further, firms in emerging countries and, more generally, firms in countries with weaker financial development or with poorly investor protection should hold more cash (Almeida et al. 2014; Pinkowitz et al. 2006).

Our study contributes to the literature on cash holdings by means of a model the purpose of which is not to describe what actually caused the financial crisis, but to show how the economy would react in the presence of excess liquidity as observed during the years before the panic of 2008. As is well documented (Taylor 2009; 2014; Mohan 2009), the years preceding the financial crisis, as well as more recent times, witnessed an accommodative monetary policy carried out by the Fed, and the existence of very low interest rates for an extended period. The latter encouraged the search for yield and risk-taking, together with a sustained rise in asset prices (particularly house prices) and the relaxation of lending standards. Therefore, the deviation of the U.S. monetary policy from economic policies that had worked well for nearly two decades brought the U.S. economy to the precipice.

Similarly, main central banks are currently engaged in a new round of monetary expansion, with the aim to reduce interest rates to strengthen the economic cycle and, in the case of the ECB, to achieve the inflation target. Thus, the huge liquidity injection in the financial markets could be used in the search for high returns to generate and feed speculative bubbles in some assets (such as real estate, securities prices traded on the exchange) leading to market instability.

As far as we are aware, only very few theoretical papers provide insights into the role of cash holdings during a period characterized by low interest rates and high liquidity. This article builds upon the work of Shaffer (1991) that explores a theoretical connection between firm behavior, chaotic time paths and price volatility by means of a microeconomic partial equilibrium model. In our model, the firm decides how to invest its cash by choosing among dividend payout, safe bonds, and risky (fixed and financial) investment. Moreover, the firm may take advantage of low interest rates and borrowing from the financial markets to increase its investment opportunities. Our paper is also related to Brunnermeier and Sannikov (2014), who study the full equilibrium dynamics of an economy with financial frictions. Due to highly nonlinear amplification effects, the economy is prone to instability and occasionally enters volatile crisis episodes. The authors show that endogenous risk due to adverse feedback loops is significantly larger away from the steady state, leading to nonlinearities: small shocks keep the economy near the stable steady state, but large shocks put the economy in the unstable crisis regime characterized by liquidity spirals.

In this vein, we develop a dynamical model for firms' decisions related to their financial activities under excess liquidity.

In this scenario, our model is intended to describe the conditions leading to the system stability and the parameters that are more destabilizing, and also leading to chaotic behavior. Our main results show which dividend-investment combinations might generate chaos. When firm increases the share of cash devoted to risky investment, and 
reduces the share of cash distributed to shareholders as dividends, the fixed point of the system changes from being stable to being unstable, and an attracting 2-cycle appears, which also becomes unstable leading to an attracting 4-cycle, and so on.

Moreover, we show that the impact of the combination of less dividends and more risky investment on the stability of the system is larger the larger the investment risk. The chaotic behavior is mainly observable in the dynamics of cash, while changes in bond value are contained within a narrow interval.

Our findings suggest that while the firm should not necessary detain less cash, firm's decision in terms of risky investment allocation may induce to the emergence of chaos. The search for riskier investment does not affect much risk-safe bond demand, while unexpected earnings (losses) might rapidly generate excess (shortfall) of cash. In turn, the unstable equilibrium, being characterized by high volatility of the firm liquidity, may move in unpredictable ways the firm from an unconstrained situation to a constrained one, with a consequent reduction of all investment opportunities.

The rest of the paper is organized as follows. Section 2 describes our discrete-time dynamic model, ultimately represented by a two-dimensional map. The equilibria and related stability are investigated in Sect. 3, while the proofs are reported in Appendix. In Sect. 3 we also show the transition to chaotic behaviors as a function of the relevant parameters. Section 4 concludes.

\section{The model}

In each period a firm decides on dividend payment $(D)$, risky investment $(I)$ and risksafe bonds $(B)$. The firm may finance its real and financial investment decisions ( $I$ and $B$ ) by borrowing funds $(L)$ from financial markets. Thus, we define $\tilde{B}_{t}$ as net bonds, that is the difference between the stock of bought bonds and borrowed loans from the financial markets, $\tilde{B}_{t}=B_{t}-L_{t}$, so that $\Delta \tilde{B}_{t}=\Delta B_{t}-\Delta L_{t}$. As corporate managers tend to upload the concept of a stable long-term payout ratio, we assume that the firm pays dividend at current period t, $D_{t}$ as a fixed proportion of its previous period cash holdings, $\Pi_{t-1}$, i.e.,

$$
D_{t}=\alpha_{1} \Pi_{t-1}
$$

where $0<\alpha_{1}<1$ is a constant. Moreover, what remains from previous period firms' cash holdings may be reinvested either in $I_{t}$ or used to buy bonds $B_{t}$, i.e.,

$$
\begin{aligned}
I_{t} & =\alpha_{2} \Pi_{t-1} \\
\Delta \tilde{B}_{t} & =\alpha_{3} \Pi_{t-1}
\end{aligned}
$$

where the positive constant $\alpha_{2} \in(0,1)$ and $\alpha_{3}$ is such that $\alpha_{1}+\alpha_{2}+\alpha_{3}=1 . \Delta \tilde{B}_{t}$ has a net rate of return equal to $i$ (which can be either positive, negative, or null) that is the spread between the interest rate on bonds minus the interest rate on loans [hence, monetary policy is summarized by the interest rate path since a change in $i$ affects firm's cash holdings (Lucas and Stokey 1987; Woodford 2003)]. We assume 
that following a decrease in interest rates, the firm is more willing to invest in real assets than to buy bonds.

Therefore we define the following identity (4) that relates firms' cash holdings $\Pi_{t-1}$ to $D, I, B$ and $L$ as follows:

$$
D_{t}+I_{t}+\Delta \tilde{B}_{t}=\Pi_{t-1}
$$

We assume that, at $t$, firm's cash holdings depends on the previous cash $\Pi_{t-1}$, the total earnings from new investment projects $R_{t}$, the net bond yields $Y_{t}$, and the portion $(1-\rho)$ of the previous-period net securities that expired and has not been renewed. Thus, firm's cash holdings evolve according to the following equation:

$$
\Pi_{t}=\Pi_{t-1}+R_{t}+Y_{t}+(1-\rho) \tilde{B}_{t-1}
$$

We model a marginal efficiency of investment (MEI) curve that declines linearly, as the reliance on external finance for some portion of investment could lead to a downward sloping net MEI curve, if external financing is more costly and used for successively greater levels of investments (Shaffer 1991). To this purpose, we define the total return on investment as a nonlinear function of $I$, as follows:

$$
R_{t}=a I_{t}-b \frac{I_{t}^{2}}{2}
$$

Thus, investment earns a marginal return according to the MEI

$$
\frac{\mathrm{d} R_{t}}{\mathrm{~d} I_{t}}=a-b I_{t}
$$

where $a$ and $b$ are positive parameters, so that $a>1, b<<1$. The parameter $a$ represents the position of the MEI line in the space $(I, \mathrm{MEI})$ and, by assuming that investment riskiness is proportional to its yield, increasing $a$ values are associated with increasing yield and riskiness (Williamson 1962). This parameter may increase over time when the firm invests in R\&D or in a growing economy. By contrast, $a$ may decrease over time when a firm fails earning above the market returns, or in the presence of a slowdown of the economy (Shaffer 1991). The parameter $b$ is related to investment adjustment costs and higher parameter values mean larger costs. Graphically, the $b$ parameter represents the slope of the MEI curve, and larger values mean a steeper line. This parameter may increase or decrease over time in relation to a change in institutions or market regulations. Indeed, $b$ quantifies the impact of frictions caused by changes in investment, and how these changes shape the adjustment costs in each period (Calcagnini et al. 2019).

As we have already mentioned, net bonds have an exogenous rate of return equal to $i$, so that earnings from net bonds are

$$
Y_{t}=i \tilde{B}_{t}
$$


and moreover, the stock of net securities is equal to the portion $\rho \in(0,1)$ of net bonds of the previous period that have not been expired (or have been renewed) plus new net bonds, i.e.,

$$
\tilde{B}_{t}=\rho \tilde{B}_{t-1}+\Delta \tilde{B}_{t}
$$

Substituting Eqs. (6) and (8) into Eq. (5), we obtain the following dynamics of $\Pi_{t}$

$$
\Pi_{t}=\Pi_{t-1}+a \alpha_{2} \Pi_{t-1}-\frac{b}{2}\left(\alpha_{2} \Pi_{t-1}\right)^{2}+i \widetilde{B}_{t}+(1-\rho) \widetilde{B}_{t-1}
$$

and the model is closed by means of Eq. (9).

Therefore, the discrete-time model in the variables $\left(\Pi_{t}, \tilde{B}_{t}\right)$ that we analyze is the two-dimensional map $\left(\Pi_{t}, \widetilde{B}_{t}\right)=T\left(\Pi_{t-1}, \widetilde{B}_{t-1}\right)$ described by the following system

$$
T:\left\{\begin{array}{l}
\Pi_{t}=-\frac{b}{2} \alpha_{2}^{2} \Pi_{t-1}^{2}+\left(1+a \alpha_{2}+i \alpha_{3}\right) \Pi_{t-1}+(i \rho+1-\rho) \widetilde{B}_{t-1} \\
\widetilde{B}_{t}=\rho \widetilde{B}_{t-1}+\alpha_{3} \Pi_{t-1}
\end{array}\right.
$$

The system (10) depends on the main exogenous variables and parameters of the model, namely: the interest rate $i$, the distribution of firms cash holdings among payment of dividends $\alpha_{1}$, investment $\alpha_{2}$ and bonds $\alpha_{3}=1-\alpha_{1}-\alpha_{2}$, as well as the portion, $\rho$, of previous-period net bonds. To simplify the notation in the following we shall use $B$ in place of $\widetilde{B}$.

\section{Equilibria and dynamics}

Let us consider the map (10). The following proposition is straightforward.

Proposition 1 The two-dimensional map $T$ in (10) has two equilibria, one at the origin $(0,0)$, and the other given by $\left(\Pi^{*}, B^{*}\right)=\left(\Pi^{*}, \frac{\alpha_{3}}{1-\rho} \Pi^{*}\right)$ where

$$
\Pi^{*}=\frac{2}{b \alpha_{2}^{2}}\left[a \alpha_{2}+i \alpha_{3}+(i \rho+1-\rho) \frac{\alpha_{3}}{1-\rho}\right]
$$

Proof From the second equation in (10) we have that it must be

$$
B^{*}=\frac{\alpha_{3}}{1-\rho} \Pi^{*}
$$

and then, from the first equation, $\Pi^{*}$ must be a solution of the following equation

$$
\Pi=-\frac{b}{2} \alpha_{2}^{2} \Pi^{2}+\left(1+a \alpha_{2}+i \alpha_{3}\right) \Pi+(i \rho+1-\rho) \frac{\alpha_{3}}{1-\rho} \Pi
$$


leading to $\Pi=0$, and thus one equilibrium is in the origin $(0,0)$, and the other solution is given explicitly in (11).

As expected, the equilibrium in the origin is unstable, as it represents a situation in which the firm has no liquidity to invest and to carry on its projects. Therefore, $\left(\Pi^{*}, B^{*}\right)=\left(\Pi^{*}, \frac{\alpha_{3}}{1-\rho} \Pi^{*}\right)$ is the equilibrium we are interested in.

It is worth noting that at the equilibrium $\left(\Pi^{*}, B^{*}\right)=\left(\Pi^{*}, \frac{\alpha_{3}}{1-\rho} \Pi^{*}\right)$ for $\alpha_{3}>0$ (that is, for $\alpha_{1}+\alpha_{2}<1$ ) the firm is investing its liquidity mainly in safe bonds. Indeed, in this situation we have that at the equilibrium both the return on investment and the MEI are negative (independently on the parameter $b$ ). That is, for $\alpha_{3}>0$, $R^{*}=a I^{*}-\frac{b}{2} I^{* 2}<0$ and $\frac{d R^{*}}{d I^{*}}=a-b I^{*}<0$.

For $\alpha_{3}<0$ the firm is borrowing from the market and investing its liquidity in risky assets yielding high returns. In this case $R^{*}>0$.

In fact, $R^{*}=a I^{*}-\frac{b}{2} I^{* 2}=I^{*}\left(a^{*}-\frac{b}{2} I^{*}\right)>0$ for $a^{*}-\frac{b}{2} I^{*}>0$ and from $I^{*}=\alpha_{2} \Pi^{*}$ (where $\Pi^{*}$ is given explicitly in (11)) we have

$$
\begin{aligned}
& a-\frac{b}{2} \alpha_{2} \Pi^{*}=a-\frac{b}{2} \alpha_{2} \frac{2}{b \alpha_{2}^{2}}\left[a \alpha_{2}+i \alpha_{3}+(i \rho+1-\rho) \frac{\alpha_{3}}{1-\rho}\right] \\
& =-\frac{\alpha_{3}}{\alpha_{2}}\left[1+\frac{i}{1-\rho}\right]
\end{aligned}
$$

and

$$
a-b I^{*}=a-b \alpha_{2} \Pi^{*}=-a-\frac{2 \alpha_{3}}{\alpha_{2}}\left[1+\frac{i}{1-\rho}\right]
$$

Differently, for $\alpha_{3}<0$ it is $R^{*}>0$, and in this case it is always $B^{*}<0$.

The following proposition, on the local stability analysis of the equilibria, is proved in the Appendix.

Proposition 2 Assuming $\rho\left(1+a \alpha_{2}+\alpha_{3}\right)>1+\alpha_{3}$ then the equilibrium point $(0,0)$ is a repelling node. The equilibrium $\left(\Pi^{*}, B^{*}\right)=\left(\Pi^{*}, \frac{\alpha_{3}}{1-\rho} \Pi^{*}\right)$ where $\Pi^{*}$ is given in (11) is an attracting node for

$$
\alpha_{1}>\alpha_{1}^{*}
$$

where

$$
\begin{aligned}
\alpha_{1}^{*}= & \alpha_{2} \frac{\left(1-\rho^{2}\right)(i-a)+(i \rho+1-\rho)(3+\rho)}{\left(1-\rho^{2}\right) i+(i \rho+1-\rho)(3+\rho)} \\
& +\frac{\left(1-\rho^{2}\right)(i-2)+(i \rho+1-\rho)(3+\rho)}{\left(1-\rho^{2}\right) i+(i \rho+1-\rho)(3+\rho)}
\end{aligned}
$$

does not depend on the parameter $b$. At $\alpha_{1}=\alpha_{1}^{*}$ the equilibrium undergoes a flip bifurcation and it is unstable for $\alpha_{1}<\alpha_{1}^{*}$. 
In our model, the assumption $\rho\left(1+a \alpha_{2}+\alpha_{3}\right)>1+\alpha_{3}$ in Proposition 2 is always satisfied as the parameter $a$ takes values much larger than 1 , while $\rho$ is close to 1 .

In Fig. 1 we show two examples of bifurcation diagrams in the parameter plane $\left(\alpha_{1}, \alpha_{2}\right)$ at two different values of the parameter $a$, keeping fixed all the other parameters at values that resemble real world economies,

$$
i=0.02, b=0.05, \rho=0.96
$$

Different values of these parameters do not change the qualitative behavior described below. 5

The bifurcation of the positive equilibrium occurs when the equality holds in (12), i.e., $\alpha_{1}=\alpha_{1}^{*}$, which is a straight line in the parameter plane $\left(\alpha_{1}, \alpha_{2}\right)$ keeping fixed all the other parameters. Crossing that line the fixed point undergoes a flip bifurcation, which may be supercritical of subcritical (Gardini et al. 2014). In our system, we have numerically verified that it is supercritical, so that soon after the flip bifurcation the fixed point becomes a saddle, and an attracting cycle of period 2 occurs.

It can be observed that increasing the parameter $a$ of the MEI the stability region of the fixed point is reduced, while the region associated with cycles or chaotic dynamics increases, that is, a wider region of chaos occurs if firms' net bonds are negative, i.e., firms borrow too much loans from the financial markets.

In Fig. 1, different colors represent regions in which the system has attracting cycles of different periods, while white points denote the existence of an attracting cycle of high period or chaotic dynamics. In yellow the stability region of the fixed point with $\Pi^{*}>0$. The blue line is the flip bifurcation line of equation $\alpha_{1}=\alpha_{1}^{*}$ where $\alpha_{1}^{*}$ is given in (12), and bounds the stability region of the fixed point, leading to the region with an attracting cycle of period 2 (region colored in pink). The colored regions show a standard transition to chaos via a sequence of period doubling bifurcations, that is cycles of period $2,4, \ldots, 2^{n} .$. , which appear and become repelling, and lead to chaotic behavior, as we shall describe below.

In Fig. 1 the diagonal of equation $\alpha_{1}+\alpha_{2}=1$ is also shown (red line), so that for parameter values of $\left(\alpha_{1}, \alpha_{2}\right)$ above that line $\alpha_{1}+\alpha_{2}>1$ and $\alpha_{3}=1-\alpha_{1}-\alpha_{2}<0$ (so that $R^{*}=a I^{*}-\frac{b}{2} I^{* 2}>0$ and $\frac{d R^{*}}{d I^{*}}=a-b I^{*}>0$ ), that is, a firm is either borrowing from the markets or issuing bonds to invest in risky assets, and distribute dividend. Below the red line $\alpha_{1}+\alpha_{2}<1$ and $\alpha_{3}=1-\alpha_{1}-\alpha_{2}>0$. In the latter

\footnotetext{
5 Parameters in 14 refer to a situation characterized by a positive interest rate spread, that is a situation in which the interest rates on borrowing are extremely low compared to interest rates on (corporate) bonds. Looking at mean bank interest rates on loans to non-financial corporation in the Euro Area, they have been well below $2 \%$ in the recent years, with a continuous decreasing trend. For example, in the last months of 2019 the interest rate on loans to non financial corporations was about $1.55 \%$ in the EA (data retrieved from https://www.euro-area-statistics.org/bank-interest-rates-loans?cr=eur\&lg=en\&page=2\&template=1). The return from corporate and treasury bonds shows larger variability. For example, the average return from Italian 10-years treasury bonds in 2019 was 1.94\%, while the return from corporate bonds (rating BBB) was generally larger, about 150 basis points for the euro area over the period 2000-2019 (see Bank of Italy (2019) p.8, Figure 1.2). In Sect. 3.1 we explore the opposite situation, in which the spread is negative. The parameter $b$ is a positive function of the investment costs (Wijkman 1962). As the latter are relatively small in the recent periods due to the low levels of interest rates, in our simulations we assume a small value of $b$. However, as stated in Proposition 2 above, $b$ does not affect the stability of the system. Finally, based also on Italian recent data, we assume $\rho$ close to 1 (Bank of Italy 2020).
} 


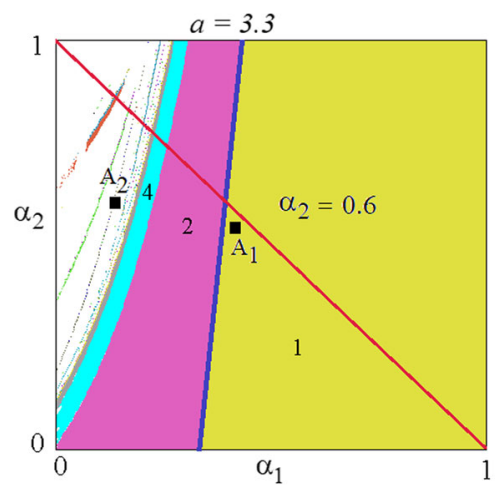

(a)

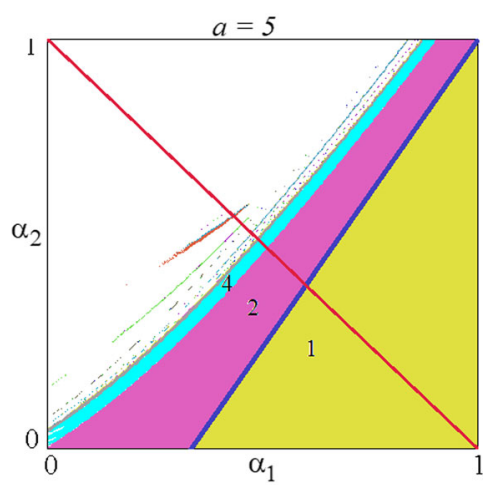

(b)

Fig. 1 Two-dimensional bifurcation diagrams in the parameter plane $\left(\alpha_{1}, \alpha_{2}\right)$ at fixed values given in (14) and $a=3.3$ in $\mathbf{a}, a=5$ in $\mathbf{b}$. The blue line is the bifurcation curve of equation $\alpha_{1}=\alpha_{1}^{*}$ given in (13). Below the diagonal of equation $\alpha_{1}+\alpha_{2}=1$ it is $\alpha_{3}>0$. The points $A_{1}$ and $A_{2}$ will be considered in Fig. 2 (color figure online)

case, then, net bonds are positive, that is the firm is also investing in safe assets. A change in the firm policy that lowers $\alpha_{1}$ (less cash to pay dividends) and increases $\alpha_{2}$ (more cash invested in risky assets) will make the system more chaotic. Furthermore, by comparing Fig. 1a with $b$, we reach the conclusion that the impact of such a policy change on the stability of the system is larger the larger the parameter $a$.

As already remarked, since the parameter $a$ captures the return of investment, larger $a$ seems to determine investment in riskier-asset and potentially over investment. Said differently, for larger $a$, meaning that investment earns larger marginal returns, the system becomes more unstable and chaotic. The underline mechanism is related to the cash holdings as follows. The return of cash often triggers large market reactions because excess cash is a function of earnings, thus revealing the earnings information to investors. Kaplan and Pérez-Cavazos (2020) show that for firms with weak (strong) investment opportunities, unexpected earnings generate excess cash rapidly (slowly). Because dividends compete with earnings announcements to supply earnings information, firms with weak (strong) investment opportunities are therefore more (less) likely to inform the market of the earnings surprise. As long as a firm holds too much cash, and $a$ is sufficiently large, the firm tends to over invest in riskier assets, generating instability.

The transition to chaos depends not only on the riskiness of investment (as captured by the parameter $a$ ), but also on the firm policies concerning the dividend payout, and the composition of firm assets portfolio ( $I$ and $B$ ), as represented by the parameters $\alpha_{1}, \alpha_{2}$, and $\alpha_{3}$, respectively. In this vein, two examples of trajectories in the phase space $(\Pi, B)$ in the case $a=3.3, \alpha_{3}>0$ and the parameter values given in (14) are shown in Fig. 2. In Fig. 2a at $\left(\alpha_{1}, \alpha_{2}\right)=(0.40,0.55)$ (see point $A_{1}$ in Fig. 1a) the fixed point $\left(\Pi^{*}, B^{*}\right)=(249.92,312.40)$ is attracting and in yellow is illustrated its basin of attraction, showing that it is quite robust, since it is far from the basin boundary. That is, a shock perturbing the state still keeps the trajectory in the basin, leading to the equilibrium. Clearly, huge shocks may also be dangerous, when bringing the system in the gray region, since the gray region denotes points having a divergent trajectory. 


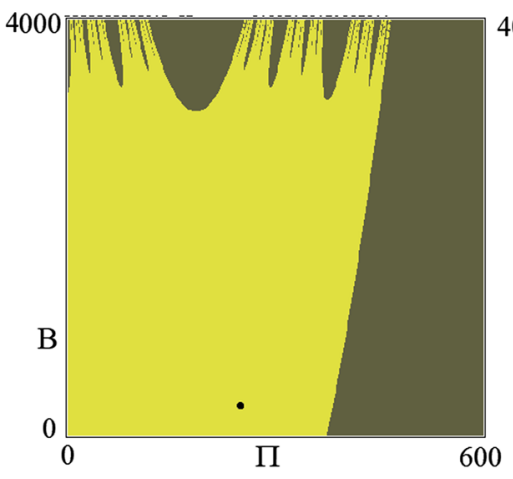

(a)

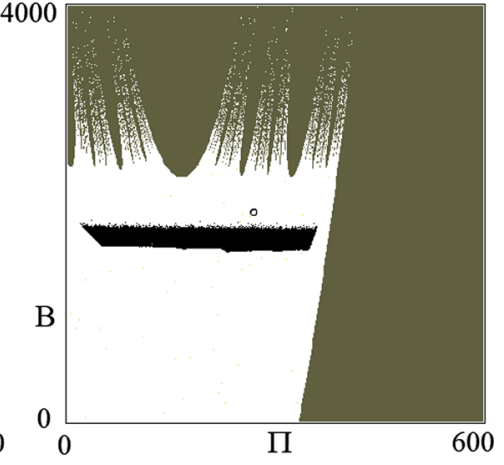

(b)

Fig. 2 The phase space in the case of positive net bonds $\left(\alpha_{3}>0\right)$. Phase space $(\Pi, B)$ represented at parameters as given in (14) and $a=3.3$. The gray region denotes points having a divergent trajectory. In a at $\left(\alpha_{1}, \alpha_{2}\right)=(0.4,0.55)$ (point $A_{1}$ in Fig. 1) the fixed point is attracting and its basin of attraction is in yellow. In $\mathbf{b}$ at $\left(\alpha_{1}, \alpha_{2}\right)=(0.1,0.6)$ (point $A_{2}$ in Fig. 1$)$, the fixed point is unstable and a chaotic attractor, and the white points belong to its basin of attraction (color figure online)

Again, following a change in cash distribution, that is decreasing the parameter $\alpha_{1}$ and increasing $\alpha_{2}$, the fixed point becomes unstable and the system becomes chaotic. This is shown in Fig. $2 \mathrm{~b}$ : at $\left(\alpha_{1}, \alpha_{2}\right)=(0.1,0.6)$ (see point $A_{2}$ of Fig. 1$)$, the fixed point $\left(\Pi^{*}, B^{*}\right)$ is unstable and we have a chaotic attracting set whose basin is shown in white. The chaotic behavior is mainly due to the $\Pi_{t}$ values, while changes in $B_{t}$ are all contained in a very narrow interval. In other words, in this case, although there is a wide chaotic range in the values of $\Pi_{t}$, the values of $B_{t}$ are not changing so much, they stay inside a small strip. However, since the values of $\Pi_{t}$ are closer to the boundary of the basin of attraction (i.e., closer to the gray region), a shock occurring when the state is in the high values may easily bring the system "to explode," i.e., a divergent trajectory may occur more likely.

Thus, from comparing Fig. 2a, b, results show that chaos occurs in the presence of a smaller share of cash for dividend payout ( $\alpha_{1}$ decreases) and a larger one for risky investment ( $\alpha_{2}$ increases). In fact, an increase in the amount of cash devoted to risky investments, generates higher probability of large fluctuations in investment returns, and, therefore, in firm's liquidity. Finally, Fig. 2 also suggests that changes in investment policy do not affect much firm financial decision related to net bonds, while unexpected earnings (losses) rapidly generate excess (shortfall) of cash.

The transition from stability to chaos can be better appreciated by looking at the one-dimensional bifurcation diagrams as a function of only one parameter, as shown in Fig. 3. For $a=3.3$ we fix the value of $\alpha_{3}=0.03$ and vary $\alpha_{1}$ in the interval $(0.1,0.5)$ (while $\alpha_{2}=1-\alpha_{1}-\alpha_{3}$ ): decreasing the value of $\alpha_{1}$ destabilizes the equilibrium. Again, increasing risky investment beyond some thresholds leads the system to instability and chaos. In other words, the system is stable for relatively larger values of $\alpha_{1}$ and smaller values of $\alpha_{2}$, while it moves to chaos when the firm decides to reduce the dividend payout in search of more profitable and riskier investments. 


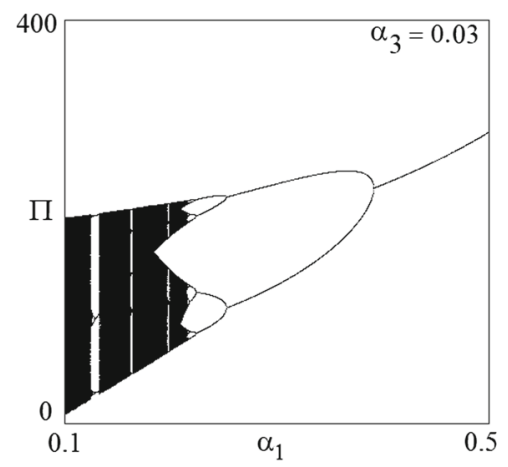

(a)

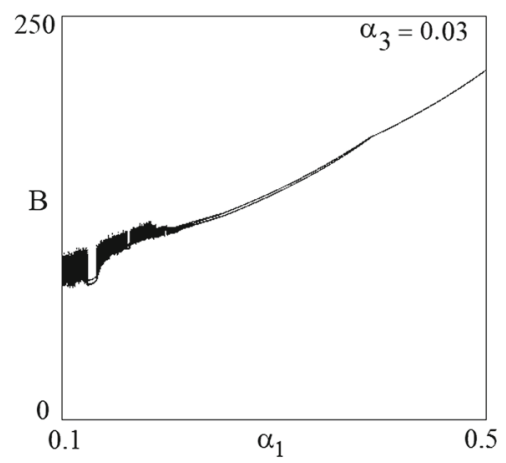

(b)

Fig. 3 One dimensional bifurcation diagrams. In $\mathbf{a}$ and $\mathbf{b}$ are shown the states of $\Pi_{t}$ and $B_{t}$ respectively, as $\alpha_{1}$ varies in the interval $(0.1,0.5)$ at $\alpha_{3}=0.03$

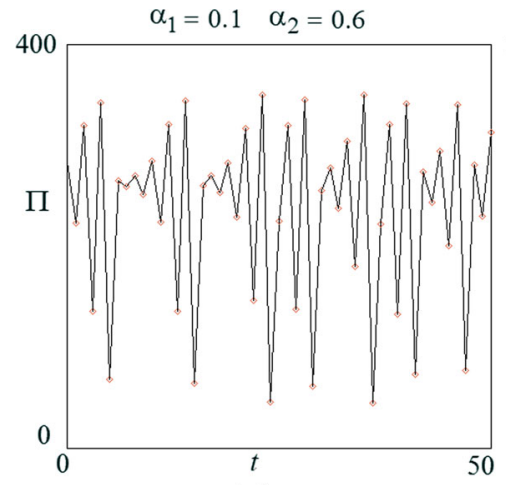

(a)

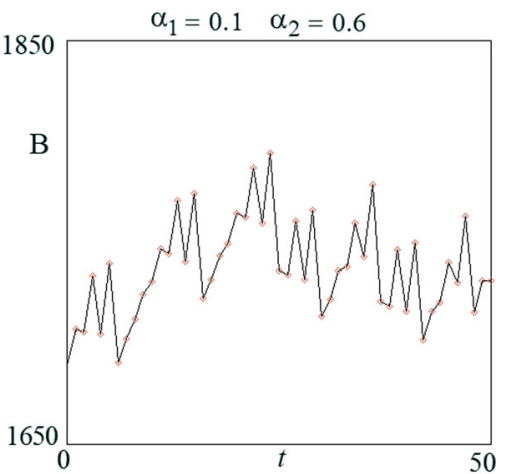

(b)

Fig. 4 Versus time trajectories. The parameters are fixed as in point $A_{2}$ in Fig. 1a, at $\alpha_{1}=0.1$ and $\alpha_{2}=0.6$, in a chaotic regime. Versus time trajectories of $\Pi_{t}$ (in a) and $B_{t}$ (in b) for 50 iterations

In Fig. 3a, we see that, by decreasing $\alpha_{1}$, the fixed point from stable becomes unstable and an attracting 2-cycle appears, which also becomes unstable leading to an attracting 4-cycle, and so on. The route to chaos is quite similar to the one which is well known for one-dimensional unimodal maps (see Medio and Lines 2001; Gandolfo 2009). Figure $3 \mathrm{~b}$ shows the dynamics of $B_{t}$, which confirms that its oscillations always occur within a small interval of values.

This can also be observed in the versus-time trajectory shown in Fig. 4 according to which the chaotic regime is never periodic, and cash holdings (Fig. 4a) fluctuate more than net bonds (Fig. 4b). Indeed, given $\alpha_{3}$, i.e., the amount of liquidity the firm invests in risk-safe bonds, the volatility of $B$ is uniquely influenced by the dynamics of cash, as shown by the equilibrium value $B^{*}=\frac{\alpha_{3}}{1-\rho} \Pi^{*}$. Furthermore, we note that when the firm is investing a large amount of cash in risky assets $\left(\alpha_{2}=0.6\right)$, the chaos occurs regardless of whether the firm is borrowing from the market or investing in safe assets ( $\alpha_{3}$ is positive in Fig. 4). 


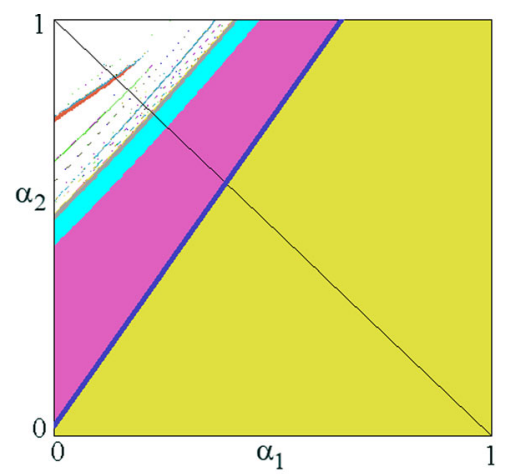

(a)

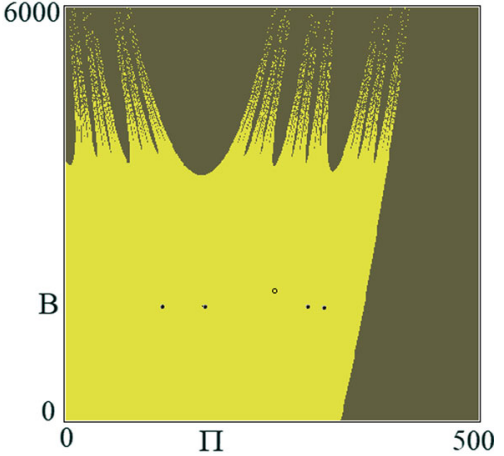

(b)

Fig. 5 In a Two-dimensional bifurcation diagram in the $\left(\alpha_{1}, \alpha_{2}\right)$ parameter plane at $i=-0.001, \rho=0.96$, $a=3.3, b=0.05$. In $\mathbf{b}$ dynamics in the phase space at the same parameters and $\alpha_{1}=0.1, \alpha_{2}=0.6$. The equilibrium is unstable and the attracting set is a cycle of period 4, its basin of attraction is in yellow. Gray points denote divergent trajectories (color figure online)

\subsection{The effects of changes in monetary policy}

During financial crises credit conditions tighten, external finance becomes more costly and cash flows decrease. Cash holdings can mitigate the impact of the crisis by providing an internal and cheaper source of funds, by avoiding inefficient liquidation of its assets to meet its obligations and prevent bankruptcy, or by serving as high-quality collateral that a firm can pledge when asset prices decline. During the recovery phase, when demand returns and credit conditions improve, cash-rich firms will have more capacity to meet this demand and can subsequently reinvest their earnings, generating additional revenue and, subsequently, investing more.

An accommodating monetary policy followed by a sudden increase in the shortterm interest rate often leads to a bubble burst and to an economic slowdown. In this vein, Giri et al. (2019) show that sudden and sharp increases of the policy rate can generate recessions, while keeping the short term interest rate anchored to the zero lower bound in the short run can successfully avoid a further slowdown.

In this section, we model a change in the monetary policy by assuming an interest rate spread close to zero but negative, while keeping all the other parameters fixed, as shown in Fig. 5. Differently from the previous Fig. 1a, which refers to a situation with a positive interest rate spread, Fig. 5a shows a larger stability region, suggesting that while borrowing frictions might depress asset values, they actually lead to a more stable equilibrium. This result occurs because in the presence of lower interest rates the amount of cash available to firms decreases, and managers have less free cash to fund risky investments.

However, as in the analyses of the previous section, as long as the firm increases investment in risky assets (increasing values of $\alpha_{2}$ ) the system moves to chaos via a sequence of period doubling bifurcations. Again, Fig. $5 \mathrm{~b}$ suggests that the perturbations of the system are mainly related to fluctuations of cash. 


\section{Conclusion}

As a response to the 2008 financial crisis, firms changed drastically their financial policies, reducing investment and indebtedness and accumulating cash to face uncertainty and system risks. Further, many central banks started engaging in deep monetary expansions to recover economies to growth. Non standard monetary policy measures generated an improvement in the liquidity stance of investment-grade and low-rated firms. While firms' working conditions are alleviated during recessions by having access to enough funds, we showed they might potentially generate economic instability.

We started by modeling firm cash holdings, and firm decisions related to dividend, financial policies and risky investment decisions. We obtained equilibria characterized by chaotic time paths, showing that too much finance, by providing wrong signals to the markets, might generate instability. Therefore, holding excessive cash might be as bad as holding excessive debt.

Our research suggests that cash volatility and fluctuations are larger the larger the share of cash invested in risky assets. The underlined mechanism is related to the fact that the firm, searching for high returns, exposes itself to the risk of cash shortfalls. The search for yield and risk-taking, together with a relaxation of lending standards, and large injections of liquidity by central banks, might be detrimental as cash fluctuations affect the future investment opportunities of firms.

Funding Open access funding provided by Universitá degli Studi di Urbino Carlo Bo within the CRUICARE Agreement.

\section{Compliance with ethical standards}

Conflict of interest The authors declare that they have no conflict of interest.

Open Access This article is licensed under a Creative Commons Attribution 4.0 International License, which permits use, sharing, adaptation, distribution and reproduction in any medium or format, as long as you give appropriate credit to the original author(s) and the source, provide a link to the Creative Commons licence, and indicate if changes were made. The images or other third party material in this article are included in the article's Creative Commons licence, unless indicated otherwise in a credit line to the material. If material is not included in the article's Creative Commons licence and your intended use is not permitted by statutory regulation or exceeds the permitted use, you will need to obtain permission directly from the copyright holder. To view a copy of this licence, visit http://creativecommons.org/licenses/by/4.0/.

\section{Appendix}

Proof of Proposition 2. The Jacobian matrix of map $T$ in (10) is given by

$$
J(\Pi, B)=\left[\begin{array}{ll}
-b \alpha_{2}^{2} \Pi+\left(1+a \alpha_{2}+i \alpha_{3}\right) & (i \rho+1-\rho) \\
\alpha_{3} & \rho
\end{array}\right]
$$


and we have to evaluate it at the equilibria, say $J^{*}$, and then the eigenvalues of its characteristic polynomial

$$
\mathcal{P}(\lambda)=\lambda^{2}-\operatorname{Tr} J^{*} \lambda+\operatorname{det} J^{*}
$$

Recall that sufficient conditions for the stability of a fixed point are given by the three conditions (see Medio and Lines 2001, Gandolfo 2009) given by

$$
\begin{aligned}
& \text { (1) : } \mathrm{P}(1)=1-\operatorname{Tr} \mathrm{J}^{*}+\operatorname{det} J^{*}>0 \\
& \text { (2) : } \mathcal{P}(-1)=1+\operatorname{Tr} J^{*}+\operatorname{det} J^{*}>0 \\
& \text { (3) : } \mathcal{P}(0)=\operatorname{det} J^{*}<1 .
\end{aligned}
$$

In the case of the origin, with $\Pi=0$, it is $\operatorname{Tr} J^{*}=1+a \alpha_{2}+i \alpha_{3}>1$ (since $a>1)$ and $\operatorname{det} J^{*}=\rho\left(1+a \alpha_{2}+\alpha_{3}\right)-\alpha_{3}$, so that the origin is a repelling node when the parameters have significant values, which lead to det $J^{*}>1$.

In the case of the fixed point $\left(\Pi^{*}, B^{*}\right)=\left(\Pi^{*}, \frac{\alpha_{3}}{1-\rho} \Pi^{*}\right)$ where $\Pi^{*}$ is given in (11) we have

$$
\begin{aligned}
\mathbf{J}^{*}\left(\Pi^{*}, B^{*}\right) & =\left[\begin{array}{ll}
-2\left[a \alpha_{2}+i \alpha_{3}+(i \rho+1-\rho) \frac{\alpha_{3}}{1-\rho}\right]+\left(1+a \alpha_{2}+i \alpha_{3}\right) & (i \rho+1-\rho) \\
\alpha_{3} & \rho
\end{array}\right] \\
& =\left[\begin{array}{ll}
1-\left(a \alpha_{2}+i \alpha_{3}\right)-\frac{2 \alpha_{3}}{1-\rho}(i \rho+1-\rho) & (i \rho+1-\rho) \\
\alpha_{3} & \rho
\end{array}\right]
\end{aligned}
$$

which is independent on the parameter $b$, and we have to consider

$$
\begin{aligned}
\operatorname{Tr} J^{*} & =\rho+1-\left(a \alpha_{2}+i \alpha_{3}\right)-\frac{2 \alpha_{3}}{1-\rho}(i \rho+1-\rho) \\
\operatorname{det}^{*} & =\rho\left[1-\left(a \alpha_{2}+i \alpha_{3}\right)-\frac{2 \alpha_{3}}{1-\rho}(i \rho+1-\rho)\right]-\alpha_{3}(i \rho+1-\rho) \\
& =\rho\left[1-\left(a \alpha_{2}+i \alpha_{3}\right)\right]-\alpha_{3}(i \rho+1-\rho) \frac{1+\rho}{1-\rho}
\end{aligned}
$$

leading to

$$
\begin{aligned}
\mathrm{P}(1) & =1-\operatorname{Tr} \mathrm{J}^{*}+\operatorname{Det}^{*} \\
& =(1-\rho)\left(a \alpha_{2}+i \alpha_{3}\right)+\alpha_{3}(i \rho+1-\rho) \\
\mathrm{P}(-1) & =1+\operatorname{TrJ}^{*}+\operatorname{Det}^{*} \\
& =2(1+\rho)-(1+\rho)\left(a \alpha_{2}+i \alpha_{3}\right)-\alpha_{3}(i \rho+1-\rho) \frac{3+\rho}{1-\rho}
\end{aligned}
$$

The condition $\operatorname{det} \mathrm{J}^{*}<1$ leads to

$$
-(1-\rho)-\rho i \alpha_{3}-\alpha_{3}(i \rho+1-\rho) \frac{1+\rho}{1-\rho}<\rho a \alpha_{2}
$$


which is always satisfied, so that this equilibrium cannot undergo a Neimark Sacker bifurcation (Simpson and Meiss 2008). Similarly, the condition $\mathcal{P}(1)>0$ is always satisfied.

The third condition $\mathcal{P}(-1)>0$ may be satisfied or not, in fact it is $\mathcal{P}(-1)>0$ for

$$
2(1+\rho)-(1+\rho)\left(a \alpha_{2}+i \alpha_{3}\right)-\alpha_{3}(i \rho+1-\rho) \frac{3+\rho}{1-\rho}>0
$$

where $\alpha_{3}=1-\alpha_{1}-\alpha_{2}$, thus for

$$
2(1+\rho)-(1+\rho) a \alpha_{2}>\left[(1+\rho) i+(i \rho+1-\rho) \frac{3+\rho}{1-\rho}\right]\left(1-\alpha_{1}-\alpha_{2}\right)
$$

and, after some algebraic steps, the condition can be written as

$$
\begin{array}{r}
\alpha_{1}>\alpha_{2} \frac{\left(1-\rho^{2}\right)(i-a)+(i \rho+1-\rho)(3+\rho)}{\left(1-\rho^{2}\right) i+(i \rho+1-\rho)(3+\rho)} \\
+\frac{\left(1-\rho^{2}\right)(i-2)+(i \rho+1-\rho)(3+\rho)}{\left(1-\rho^{2}\right) i+(i \rho+1-\rho)(3+\rho)}
\end{array}
$$

leading to $\alpha_{1}^{*}$ as given in (13). The condition $\mathcal{P}(-1)>0$ is satisfied for $\alpha_{1}>\alpha_{1}^{*}$.

\section{References}

Acharya VA, Almeida H, Campello M (2007) Is cash negative debt? A hedging perspective on corporate financial policies. J Financ Intermed 16:515-554

Adao B, Silva AC (2019) The effect of firm cash holdings on monetary policy. Available at SSRN: https:// ssrn.com/abstract=2635727 or https://doi.org/10.2139/ssrn.2635727

Adler K, Ahn J, Dao M (2019) Innovation and corporate cash holdings in the era of globalization. IMF working paper WP/19/17. Available at: https:/www.imf.org/en/Publications/WP/Issues/2019/01/18/ Innovation-and-Corporate-Cash-Holdings-in-the-Era-of-Globalization-46494

Ahir H, Bloom N, Furceri D (2018) The World Uncertainty Index. Stanford mimeo

Almeida H, Campello M, Weisbach MS (2004) The cash flow sensitivity of cash. J Finance 59:1777-1804

Almeida H, Campello M, Cunha I, Weisbach M (2014) Corporate liquidity management: a conceptual framework and survey. Ann Rev Financ Econ 6:135-162

Backer SR, Bloom N, Davis SJ (2019) Economic policy uncertainty. https://www.policyuncertainty.com/ index.html

Bank of Italy (2020) Relazione Annuale anno 2019. Roma

Bank of Italy (2019) Rapporto sulla stabilità finanziaria 2. Roma

Bates TW, Kahle KM, Stulz RM (2009) Why Do U.S. Firms hold so much more cash than they used to? J Finance 64(5):1985-2021

Baumol WJ (1952) The transactions demand for cash: an inventory theoretic approach. Q J Econ 66(4):545556

Blanchard OJ, Lopez-de-Silanes F, Shleifer A (1994) What do firms do with cash windfalls? J Financ Econ 36:337-360

Bover O, Watson N (2005) Are there economies of scale in the demand for money by firms? Some panel data estimates. J Monet Econ 52(8):1569-1589

Brunnermeier MK, Sannikov Y (2014) A macroeconomic model with a financial sector. Am Econ Rev 104:379-421

Calcagnini G, Gehr A, Giombini G (2009) Cash holdings, firm value and the role of market imperfections. a cross country analysis. In: The economics of imperfect markets. Springer, pp 51-71 
Calcagnini G, Giombini G, Travaglini G (2019) A theoretical model of imperfect markets and investment. Struct Change Econ Dyn 50:237-244

Campello M, Giambona E, Graham JR, Harvey CR (2011) Liquidity management and corporate investment during a financial crisis. Rev Financ Stud 24(6):1944-1976

Dottori D, Micucci G (2018) Corporate liquidity in Italy and its increase in the long recession. Econ Polit J Anal Inst Econ 35(3):981-1014

Faulkender MW, Hankins KW, Petersen MA (2019) Understanding the rise in corporate cash: precautionary savings or foreign taxes. Rev Financ Stud 32(9):3299-3334

Frenkel JA, Jovanovic B (1980) On transactions and precautionary demand for money. Q J Econ 95(1):25-43

Gandolfo G (2009) Economic dynamics. Springer, Heidelberg

Gardini L, Avrutin V, Sushko I (2014) Codimension-2 border collision bifurcations in one-dimensional discontinuous piecewise smooth maps. Int J Bifurc Chaos 24(2):1450024

Gatti S, Chiarella C (2014) Deleveraging, investing and optimizing capital structure. Centre for Applied Research in Finance, Università Commerciale Luigi Bocconi, Milano

Gilchrist S, Himmelberg CP (1995) Evidence on the role of cash flow for investment. J Monet Econ 36:541572

Gilchrist S, Sim JW, Zakrajsek E (2013) Misallocation and financial market frictions: some direct evidence from the dispersion in borrowing costs. Rev Econ Dyn 16:159-176

Gilchrist S, Yankov V, Zakrajsek E (2009) Credit market shocks and economic fluctuations: evidence from corporate bond and stock markets. J Monet Econ 56:471-493

Giri F, Riccetti L, Russo A, Gallegati M (2019) Monetary policy and large crises in a financial accelerator agent-based model. J Econ Behav Organ 157:42-58

Harford J (1999) Corporate cash reserves and acquisitions. J Finance 54(6):1969-1997

Kalcheva I, Lins KV (2007) International evidence on cash holdings and expected managerial agency problems. Rev Financ Stud 20(4):1087-1112

Kaplan Zachary, Pérez-Cavazos Gerardo (2020) Investment as the opportunity cost of dividend signaling. Available at SSRN: https://ssrn.com/abstract=3393065 or https://doi.org/10.2139/ssrn.3393065

Kim C-S, Mauer DC, Sherman AE (1998) The determinants of corporate liquidity: theory and evidence. J Financ Quant Anal 33:335-359

Jensen M (1986) Agency costs of free cash flow, corporate finance and takeovers. Am Econ Rev 76(2):323329

Jensen M, Meckling W (1976) Theory of the firm: managerial behavior, agency costs and ownership structure. J Financ Econ 3:305-360

Joseph A, Kneer C, van Horen N, Saleheen J (2020) All you need is cash: corporate cash holdings and investment after the financial crisis. CEPR Discussion Paper No. DP14199

Lucas RE, Stokey NL (1987) Money and interest in a cash-in-advance economy. Econometrica 55(3):491513

Medio A, Lines M (2001) Nonlinear dynamics: a primer. Cambridge University Press, Cambridge

Miller MH, Orr D (1966) A model of the demand for money by firms. Q J Econ 80(3):413-435

Miller MH, Orr D (1968) A model of the demand for money by firms: extension of analytical results. J Finance XXII I(5):735-759

Mohan R (2009) Global financial crisis? Causes, impact, policy responses and lessons. BIS Rev 54

Opler T, Pinkowitz L, Stulz RM, Williamson R (1999) The determinants and implications of corporate cash holdings. J Financ Econ 52:3-46

Ozkan A, Ozkan N (2004) Corporate cash holdings: an empirical investigation of UK companies. J Bank Finance 28:2103-2134

Picard R (2011) Too much cash becomes a really serious business problem. Forbes,https://www.forbes. $\mathrm{com} /$ sites/robertpicard/2011/08/08/liguidity-is-creating-short-term-investment-challenges-formany-companies/

Pinkowitz L, Stulz R, Williamson R (2006) Does the contribution of corporate cash holdings and dividends to firm value depend on governance? A cross-country analysis. J Finance 61(6):2725-2751

Pinkowitz L, Stulz R, Williamson R (2015) Do U.S. firms hold more cash than foreign firms do? Rev Financ Stud 29(2):2016

Sanchez JM, Yurdagul E (2013) Why are corporations holding so much cash? The Regional Economist, Federal Reserve of St. Louis, January

Shaffer S (1991) Structural shifts and the volatility of chaotic markets. J Econ Behav Organ 15:201-214 
Simpson DJW, Meiss JD (2008) Neimark-Sacker bifurcations in planar, piecewise-smooth, continuous maps. SIAM J Appl Dyn Syst 7

Taylor J (2009) The financial crisis and the policy responses: an empirical analysis of what went wrong. Working Paper 14631, January, National Bureau of Economic Research

Taylor JB (2014) Causes of the financial crisis and the slow recoverya ten-year perspective. In: Baily MN, Taylor JB (eds) Across the great divide: new perspectives on the financial crisis. Hoover Institution Press, Washington, DC

Tobin J (1956) The interest-elasticity of transactions demand for cash. Rev Econ Stat 38(3):241-247

Yun H (2009) The choice of corporate liquidity and corporate governance. Rev Financ Stud 22(4):14471475

Wijkman PE (1962) The marginal efficiency of capital and of investment; A didactic exercise. Swed J Econ 67(4):263-278

Williamson OE (1962) The elasticity of the marginal efficiency function: comment. Am Econ Rev 52(5):1099-1103

Woodford M (2003) Interest and prices: foundations of a theory of monetary policy. Princeton University Press, Princeton. ISBN: 0691010498

Publisher's Note Springer Nature remains neutral with regard to jurisdictional claims in published maps and institutional affiliations. 